\title{
Role of Lung Fluid Volume in Growth and Maturation of the Fetal Sheep Lung
}

\author{
A. C. Moessinger, R. Harding, T. M. Adamson, M. Singh, and G. T. Kiu \\ Departments of Pediatrics and Pathology, College of Physicians \& Surgeons of Columbia University, New York 10032; \\ and the Departments of Physiology and Pediatrics, Monash University, Melbourne, Australia
}

\begin{abstract}
We studied the effects of alterations in lung fluid volume on growth and maturation of the fetal lung. In a chronic fetal sheep preparation, right fetal lung volume was decreased by drainage of lung fluid while the volume of the left lung was expanded by mainstem bronchus ligation leading to lung fluid retention. After an experimental period of $25 \mathrm{~d}$ (from 105 to $129 \mathrm{~d}$ of gestation, term $=145 \mathrm{~d}$ ), the right (deflated) lung was significantly hypoplastic and contained less DNA than the controls; $175.15 \pm 55.18$ vs. $346.77 \pm 61.97 \mathrm{mg}$, respectively; $P$ $<0.001$. In contrast, the left (expanded) lung was significantly hyperplastic and contained more DNA than the controls; $390.74 \pm 103.53$ vs. $238.85 \pm 33.32 \mathrm{mg}$, respectively; $P=0.001$.

Biochemical indices of lung maturation, including total phospholipids, phosphatidylcholine, and disaturated phosphatidylcholine content expressed per unit of tissue DNA, were no different when comparing the hypoplastic, hyperplastic, and control lungs. These findings demonstrate that fetal lung cell multiplication is influenced by local distension with lung fluid, while the biochemical maturation of fetal lung surfactant is under systemic control. (J. Clin. Invest. 1990. 86:1270-1277.) Key words: lung hypoplasia - hyperplasia - development of larynx $\bullet$ trachea $\bullet$ thorax
\end{abstract}

\section{Introduction}

Anomalies in size and structure of the lung are the leading cause of premature mortality due to congenital anomalies in the United States (1). In a recent necropsy series of early neonatal deaths (2), the prevalence of lung hypoplasia was found to have risen as a result of a shift in proportionate mortality. Fewer newborn infants are now dying of other pulmonary diseases, such as hyaline membrane disease, meconium aspiration, and pneumonia, while the number of patients dying with lung hypoplasia has remained constant (2). When considering infants born at or above 35 wk of gestation, as many as onethird of all early neonatal deaths are associated with lung hypoplasia (2). It has therefore become imperative to improve our understanding of the physiopathology involved in derangements of normal lung development.

This work was presented in May 1989 at the annual meeting for The Society for Pediatric Research, Washington, DC.

Address correspondence and reprint requests to Dr. A. C. Moessinger, Babies Hospital, Box 34, C.P.M.C., 3975 Broadway, New York, NY 10032.

Received for publication 26 March 1990 and in revised form 18 May 1990.

J. Clin. Invest.

(c) The American Society for Clinical Investigation, Inc.

$0021-9738 / 90 / 10 / 1270 / 08 \$ 2.00$

Volume 86, October 1990, 1270-1277
There is now strong evidence that fetal lung volume must be maintained within its physiologic range for normal lung growth to occur $(3,4)$. Transpulmonary pressure, a major determinant of lung liquid volume, is determined in the fetus by pleural pressure and the secretion pressure of lung liquid acting against a resistance to outflow in the upper airways $(5,6)$. Experimental manipulations of transpulmonary pressure have led to abnormal lung volumes and lung growth $(7,8)$. Extreme manipulations of upper airway resistance have led to opposing effects on lung expansion and growth. Chronic tracheal obstruction resulted in increased distention and growth of the fetal lungs $(9,10,11)$, whereas chronic drainage of lung fluid seemed to arrest fetal lung growth (11). In a study of lung morphology in fetal sheep, Alcorn et al. (11) documented that chronic tracheal drainage led to decreased lung tissue weight while chronic tracheal ligation led to lung distention and increased lung tissue weight. These findings did not include measurements of DNA content (cell number); nevertheless, they did suggest that lung development was influenced by local distending forces related to the volume of fetal lung fluid retained within the future airways, the fluid apparently acting as an "internal splint" around which the lung grew.

An unexpected finding in the study of Alcorn et al. (11) was that chronic lung fluid drainage appeared to advance lung maturation while lung fluid retention had the opposite effect. Lung maturation was evaluated by the ratio of type II to type I pneumocytes and this ratio was higher in the drained lungs, and lower in the distended lungs, leading to the additional hypothesis that lung maturation, as well as lung growth, is determined by local factors. The current view that lung maturation is under the control of systemic hormones $(4,5)$ should be noted.

Indirect evidence, derived from both animal studies and experiments of nature, supports the crucial role played by fetal lung fluid volume in the control of lung growth. Tracheal ligation in the fetal rabbit prevents the lung hypoplasia that normally follows the abolition of fetal breathing movements induced by cervical cord section (12). The lung hypoplasia commonly found in association with renal agenesis and oligohydramnios in human fetuses (13) is not seen when laryngeal atresia is also present $(14,15)$. Although the large lungs found in association with laryngeal atresia have been described as hyperplastic $(15,16)$, in cases where lung DNA (and DSPC) contents were determined, these were found to be within the normal range (14).

Given the potential importance of the hypotheses of Alcorn et al. (11), the lack of available data on lung cell number and surfactant content, and the apparent controversy on the magnitude of the effect of tracheal obstruction on lung cell multiplication, it was decided to complement these observations using a new approach. Previous studies have used two groups of fetuses, one for tracheal drainage and the other for tracheal ligation. This study uses only one group in which each 


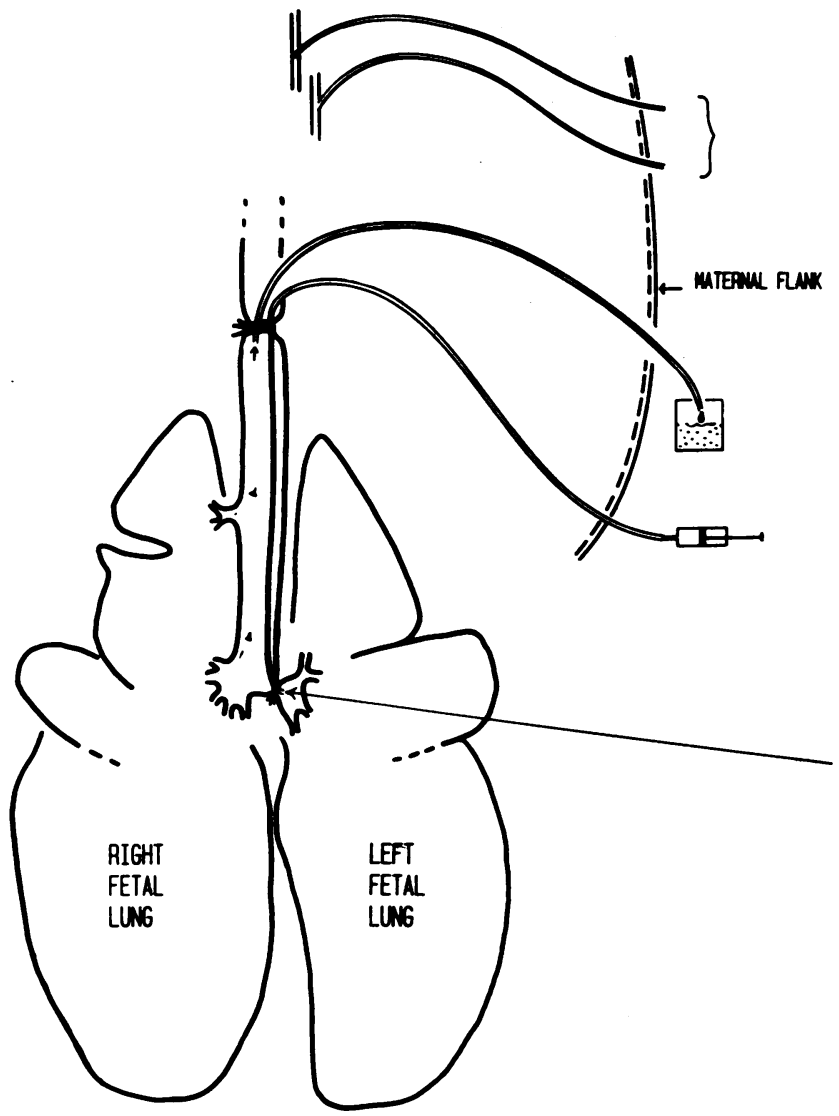

fetus underwent drainage of one lung and mainstem bronchus ligation of the opposite lung. Thus, if the above hypotheses were true, the drained lung should be both hypoplastic and hypermature, while the ligated lung is hyperplastic and hypomature despite a common endocrine milieu. A preliminary account of this experiment has been presented previously (17).

\section{Methods}

10 ewes, 7 with twin and 3 with single fetuses, $100-110 \mathrm{~d}$ pregnant, were anesthetized with halothane in $\mathrm{O}_{2}$ and $\mathrm{N}_{2} \mathrm{O}$ (50:50, vol/vol). In the twin pregnancies, one fetus was used as either an experimental or a sham-operated animal while the twin fetus was used as an untouched littermate control. Of the singletons, two were used as experimental animals and one as a sham-operated animal. Using sterile surgical techniques, catheters were inserted into carotid arteries and jugular veins of both the ewe and the fetus. In the experimental fetuses, the mid-cervical trachea was ligated around a catheter, the tip of which was located above the carina (Fig. 1). This catheter was used to drain fluid from the right lung. In order to prevent the outflow of luminal liquid from the left lung, the left mainstem bronchus (LMSB) ${ }^{1}$ was obstructed, thereby leading to left lung overexpansion. The LMSB was exposed via a right intercostal thoracotomy (6-7th intercostal space); it was dissected free of surrounding tissue, care being taken not to disrupt the visceral pleura. In four of the experimental animals, a second catheter was introduced into the trachea and the tip advanced until it entered the LMSB. The LMSB was then firmly ligated (around the luminal catheter in four fetuses) with a double loop of No. 0 silk suture and the fetal chest was closed. For the sham-operated animals $(n=3)$, a nonobstructive tracheal catheter was inserted; the thoracotomy and

1. Abbreviations used in this paper: DSPC, disaturated phosphatidylcholine; LMSB, left mainstem bronchus.
FETAL VASCULAR

CATHETERS

TRACHEAL CATHETER

DRAINING RIGHT LUNG LIQUID

TO ATMOSPHERIC PRESSURE

LEFT LUNG LIQUID,

CATHETER CLOSED

\section{LEFT MAINSTEM BRONCHUS LIGATURE}

Figure 1. Diagram of the fetal sheep lungs (anterior view) illustrating the surgical preparation, the position of the tracheal catheters, and ligature. Following ligature of the left mainstem bronchus, the upper tracheal catheter is used to drain right fetal lung fluid. the left mainstem bronchus

LMSB dissection were performed in a similar fashion except that the mainstem bronchus was not ligated. Amniotic catheters were placed and the uterus closed. All catheters were exteriorized through the ewe's flank, (see Fig. 1).

After recovery from anesthesia, the larger (upper) tracheal catheter of the experimental fetuses (essentially connected to the right lung) was open to drainage at atmospheric pressure. The lung fluid from the right lung was continuously drained in a sterile bag attached to the ewe's cage (below the level of the uterus) throughout the experimental period which began at $105 \pm 4$ (SD) $d$ of gestation (range 100-111) and ended at $129 \pm 2 \mathrm{~d}$ (range 125-131). The smaller catheter placed in the ligated LMSB of four fetuses was kept closed except for sampling of small volumes of lung fluid (2-3 ml) every 3-5 d. The same protocol of lung fluid sampling was followed for the sham-operated animals. Fetal acid-base status was determined daily and samples of blood and amniotic fluid were taken every 3-5 d for hormone measurements.

At the conclusion of the experimental period, the duration of which was $25 \pm 4$ (SD) d, the ewe was killed and a second laparotomy was performed; amniotic fluid volume was determined, and the fetuses were given a lethal dose of pentobarbital. Fetal lung fluid volumes were determined by removing as much fluid as possible with a syringe. Trachael cannulae were swiftly inserted in the untouched littermate controls for the same measurements at the time of death. A complete necropsy was performed, including verification of catheter placements and the effectiveness of the left mainstem bronchus ligation. Thin coronal sections of the lung were cut from the right middle lobe and from the apex of the left lower lobe, weighed, and fixed in formaldehyde. The remainder of the lungs ( $>90 \%$ ) were frozen and lyophylized, after partitioning into left and right as well as upper and lower portions of the organ. In citing the dry weights below (see results), we assumed that the dry/wet weight ratios of the small samples of lung tissue used for histology were the same as that measured in the remainder of the lung.

DNA was extracted according to the method of Munro and Fleck 
(18) and measured by ultraviolet absorption. Protein content was determined by the method of Lowry (19). Total lipids were extracted by the procedure of Folch (20) and total phospholipid phosphorus was estimated by the procedure of Bartlett (21). Phosphatidylcholine was isolated from total lipid extracts by thin layer chromatography and disaturated phosphatidylcholine was isolated using the osmium tetroxide method of Mason (22). The recovery rate was $>95 \%$ for total phospholipids and $\mathbf{8 7 - 9 0 \%}$ for disaturated phosphatidylcholine. Hydroxyproline was determined by a modification of the method of Prockop and Udenfriend (23). Cortisol concentrations in fetal plasma were measured by radioimmunoassay, using the same antisera and procedure as described previously (24). Epinephrine concentrations in fetal plasma were determined using high performance liquid chromatography followed by electrochemical detection (25).

Comparisons of differences between the measurements obtained from control and experimental fetuses were performed using two sample $t$ tests. Because of the relatively small number of animals studied and the large number of variables available, $\sim 20$, we assigned a penalty for the significance of the $P$ value according to the formula: $0.05 / 20=0.0025$. Comparisons yielding a $P$ value below this number were considered statistically significant.

\section{Results}

In five of the seven experimental fetuses, the ligation of the LMSB led to complete obstruction. In the other two fetuses (without catheters in the LMSB) sections of the ligature site demonstrated the persistence of a lumen of less than $1 \mathrm{~mm}$ confirmed by light microscopy. These two fetuses were excluded from the experimental group $(n=5)$ before further analyses and are described separately.

Fetal acid-base status, plasma epinephrine, and cortisol levels were in the normal range for gestational age and there was no apparent difference between experimental and shamoperated groups (Table I). The mean volume of fetal lung fluid drained from the right lung over the experimental period was

Table I. Acid-base, Catechole, and Cortisol Serum Levels

\begin{tabular}{|c|c|c|}
\hline Measurement & $\begin{array}{l}\text { Experimental } \\
\qquad(n=5)\end{array}$ & $\begin{array}{l}\text { Sham-operated } \\
\qquad(n=3)\end{array}$ \\
\hline & mean (range) & mean (range) \\
\hline pH, start & $7.36(7.32-7.38)$ & $7.38(7.34-7.40)$ \\
\hline $\mathrm{PaCO}_{2}(\mathrm{mmHg})$, start & $43(34-48)$ & $39(35-42)$ \\
\hline $\mathrm{PaO}_{2}(\mathrm{mmHg})$, start & $23(14-31)$ & $27(20-33)$ \\
\hline pH, end & $7.33(7.32-7.36)$ & $7.35(7.33-7.35)$ \\
\hline $\mathrm{PaCO}_{2}(\mathrm{mmHg})$, end & $47(37-52)$ & $44(38-49)$ \\
\hline $\mathrm{PaO}_{2}(\mathrm{mmHg})$, end & $23(20-30)$ & $25(24-26)$ \\
\hline Epinephrine, start, $\mathrm{pg} / \mathrm{ml}$ & $131(60-333)$ & $276(96-524)$ \\
\hline Epinephrine, end, pg/ml & $149(4-372)$ & $156(93-250)$ \\
\hline Cortisol, start, ng/ml & $2.7(1.8-5.0)$ & $4.2(2.4-5.4)$ \\
\hline Cortisol, end, ng/ml & $3.9(1.2-8.6)$ & $6.4(4.3-8.4)$ \\
\hline Amniotic fluid volume, $\mathrm{ml}$ & $286(65-580)$ & $640(320-800)$ \\
\hline Lung fluid drained, right, 1 & $2.5(1.1-3.8)$ & - \\
\hline Rate of drainage, $\mathrm{ml} / \mathrm{hr}$ & $4.4(1.9-6.6)$ & - \\
\hline
\end{tabular}

Amniotic fluid volume at death and fetal lung fluid volume drained from the right lung during the experimental period.

Mean \pm SD duration of experiment was $25 \pm 4 \mathrm{~d}(105 \pm 4$ to $129 \pm 2)$.

The start values for $\mathrm{pH}, \mathrm{PaCO}_{2}$, and $\mathrm{PaO}_{2}$ are those of the first postoperative day. The start values for epinephrine and cortisol were obtained on the third postoperative day (mean $=109$ ).
2.5 liters, leading to a calculated flow rate over the entire study period of $4.4 \mathrm{ml} / \mathrm{h}$. The mean amniotic fluid volume in the experimental animals was $286 \mathrm{ml}$, which was not significantly less $(P=0.116)$ than the $640 \mathrm{ml}$ found in the sham-operated group (Table I).

All fetuses were alive at the time of the cesarean section. No anomalies were noted during the external examinations of the fetal bodies. At the time of dissection, however, we noted that the chest was slightly asymmetrical in the experimental fetuses with a prominent left hemithorax and an inverted diaphragm on the left side (Fig. 2). Upon opening the chest cavity, we saw no marked mediastinal shift despite the fact that the lung was clearly smaller on the right and larger on the left side in the experimental animals (Fig. 3). This asymmetry was even more manifest after en bloc dissection of the lungs (Fig. 4).

The fetal body and organ measurements were found to be identical when comparing the three sham-operated to the seven untouched twin controls. The data from these 10 fetuses ( 5 males and 5 females) were therefore pooled for comparison with those of the five successful experimental animals (one male and four females); the results, expressed in percent of control values, are presented in Table II. The only significant differences were in the lung measurements. For the experimental animals, right lung fluid volume was $7 \%$ and left lung fluid volume was $388 \%$ of controls $(P<0.001$ for both comparisons). The control values for right and left fetal lung fluid volumes were estimated, based on the determined total lung fluid volume and the respective wet and dry weights of each lung in sham-operated and unoperated fetuses. In these fetuses, the weight of the left lung was $39.7 \%$ of total lung for wet weight and $40.4 \%$ for dry weight; values of $40 \%$ of total lung fluid volume for the left and $60 \%$ for the right lung were therefore used. These derived values for right and left lung fluid volumes are slight overestimates since they include an unknown volume of fluid contained in the trachea below the catheter insertion site. Wet lung weights were $42 \%$ of controls for the drained right side (experimental, 24.71 17.96 ; control, $59.59 \pm 8.39 \mathrm{~g}$ ) and $319 \%$ of controls for the ligated left side (experimental, 125.28 \pm 39.61 ; control, $39.23 \pm 4.80 \mathrm{~g}$ ), with both comparisons yielding statistically significant differences ( $P$ values $<0.001$ ). It should be noted that the wet lung weights were obtained after removal of as much lung fluid as possible. The left lungs in the experimental group proved to be more difficult to drain completely with consistency because of the existing left mainstem bronchus ligation.

Table III gives the results of the analyses of lung tissue. The dry weights of the drained lungs were reduced by half while those of the ligated lungs were nearly double the control values. Lung cell number, determined by total lung DNA content, was significantly less following drainage of fetal lung fluid $(P<0.001)$, confirming the presence of hypoplasia, and significantly more after mainstem bronchus obstruction and fetal lung fluid retention $(P=0.001)$, confirming hyperplasia. There were no significant differences in the other measurements, including indices of lung maturation (Table III).

As mentioned above, the ligation of the left mainstem bronchus was not complete in two animals, because of the persistence of a pinhole tract. During the experimental period, the tracheal catheter drained not only right lung fluid but some fluid from the left lung as well. The mean volume drained in these two animals was 3.2 liters (3.3 and 3.1 liters) and the 

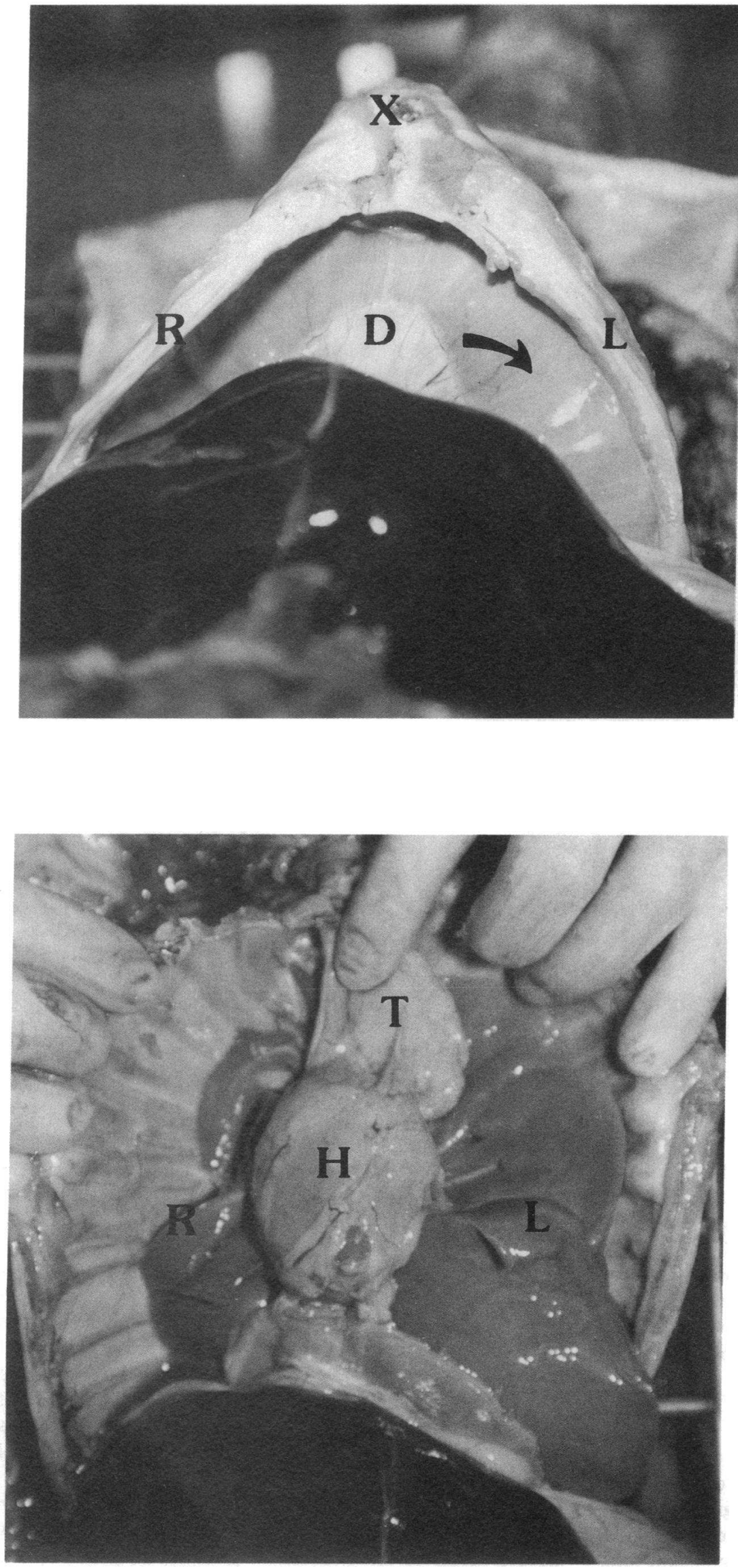

Figure 2. Abdominal view of the diaphragm and the ribcage. $X$, xyphoid process; $D$, diaphragm; $L$, left; and $R$, right. The anterolateral aspect of the ribcage is flat on the right and convex on the left side; as a result, the width of the right hemithorax is less, and that of the left hemithorax is more than in controls. Note that the left hemidiaphragm is inverted (arrow).
Figure 3. Anterior view of the opened chest showing the mediastinum with the heart $(H)$ and the thymus $(T)$ in a midline position. $R$, right lung; and $L$, left lung. Note the discrepancy in size of the lungs. 


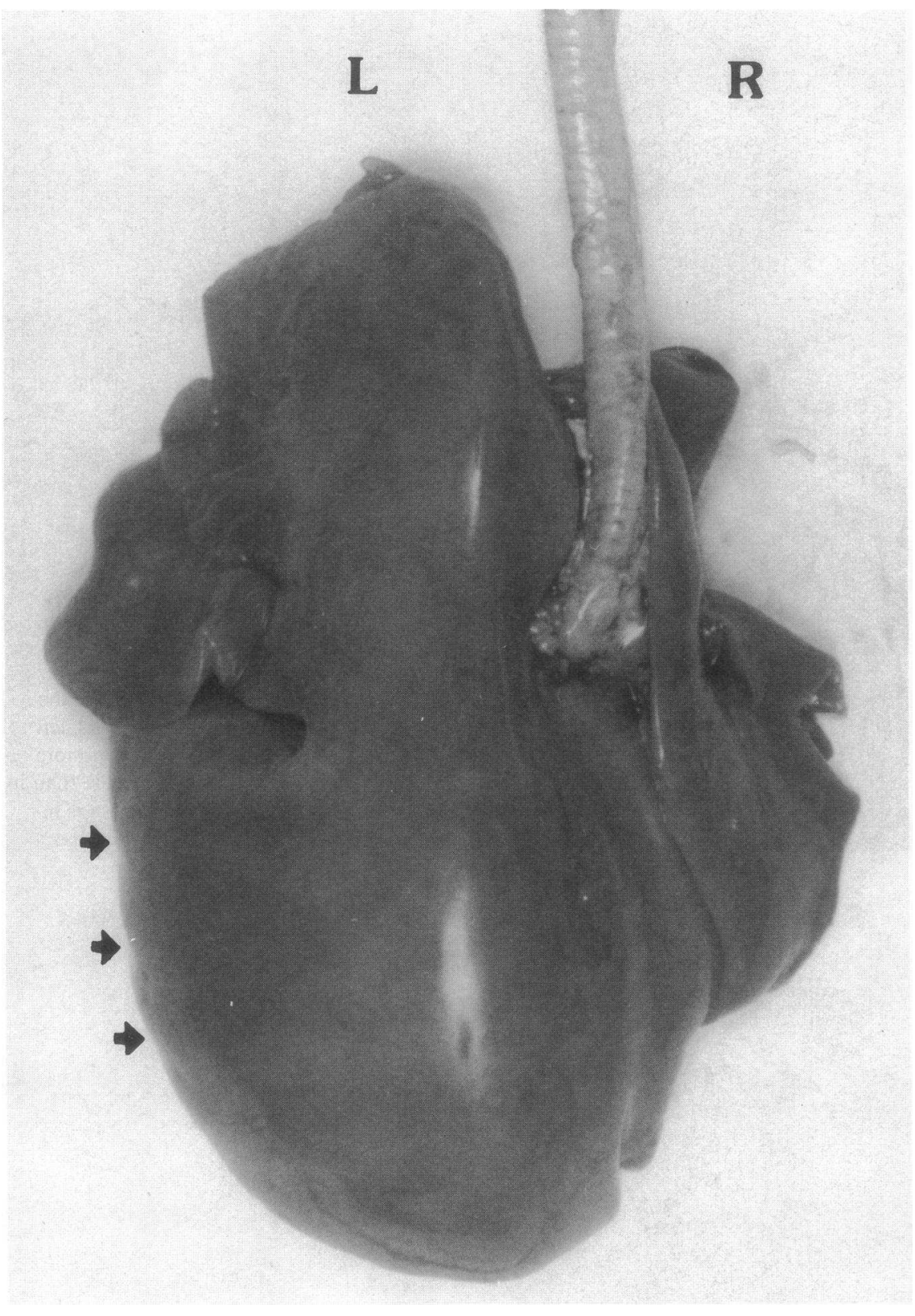

Figure 4. Posterior view of the lungs en bloc showing the impact of chronic fetal lung fluid retention on the left lung $(L)$ which became hyperplastic, and that of chronic lung fluid drainage on the right lung $(R)$ which became hypoplastic. Note the indentations on the left pleural surface (arrows) caused by pressure against the ribs. calculated flow rate was $6.1 \mathrm{ml} / \mathrm{h}(5.8$ and $6.4 \mathrm{ml} / \mathrm{h})$, slightly in excess of the experimental values presented in Table I. Mean dry lung weight and DNA content of the right lungs were 3.583 $\mathrm{g}(2.891$ and $4.274 \mathrm{~g})$ and $186.31 \mathrm{mg}(158.92$ and $213.17 \mathrm{mg}$ ), respectively, within 1 SD of the experimental values presented in Table III. For the left lung, however, these same measurements were $4.036 \mathrm{~g}(3.282$ and $4.789 \mathrm{~g})$ and $210.64 \mathrm{mg}(181.82$ and $239.45 \mathrm{mg}$ ), respectively, within the range of the control values presented in Table III.

\section{Discussion}

This study has demonstrated clearly that local distension by lung liquid is a major determinant of fetal lung growth. For in the same animal, chronic deflation by drainage of lung liquid from one lung results in the development of significant lung hypoplasia, while chronic overexpansion by retention of fetal lung fluid from the other lung results in significant lung hyperplasia. These diagnoses were documented by measurements of DNA contents, a reflection of cell number. These findings confirm the observation of Alcorn et al. (11) in which the diagnoses of lung hypo- and hyperplasia were based on measurements of wet lung tissue weight. The magnitude of the effect on lung growth observed in both studies is similar, as were the durations and gestational ages of the experimental periods. In the study of Alcorn et al. (11), lung tissue weights of the drained and ligated lungs represented 48 and $207 \%$ of control values, respectively. In the present study, dry weights of the drained and ligated lung were 49 and $181 \%$ of control values, respectively.

In contrast to the similarity of results on lung growth in both studies, we did not observe any influence of either lung fluid drainage or retention on lung maturation. Total phospholipids, phosphatidylcholine, and disaturated phosphatidyl- 
Table II. Body Measurements and Organ Weights for Experimental and Control Fetuses at 129 d of Gestation

\begin{tabular}{|c|c|c|c|}
\hline Measurements & $\begin{array}{l}\text { Experimental } \\
\qquad(n=5)\end{array}$ & $\begin{array}{l}\text { Control } \\
(n=10)\end{array}$ & $\%$ of Control \\
\hline Body length, crown to rump $(\mathrm{cm})$ & $42.86 \pm 5.11$ & $44.57 \pm 2.50$ & 96 \\
\hline Body weight $(g)$ & $3464 \pm 1218$ & $3572 \pm 598$ & 97 \\
\hline Lung fluid volume ( $\mathrm{ml}$ right) ${ }^{\ddagger}$ & $1.6 \pm 0.5^{*}$ & $21.5 \pm 6.0$ & 7 \\
\hline Lung fluid volume (ml left) $)^{\ddagger}$ & $55.7 \pm 19.0^{*}$ & $14.4 \pm 4.0$ & 388 \\
\hline Right lung wt (wet, $g$ ) & $24.71 \pm 7.96^{*}$ & $59.59 \pm 8.39$ & 42 \\
\hline Left lung wt, wet $(g)$ & $125.28 \pm 39.61^{*}$ & $39.23 \pm 4.80$ & 319 \\
\hline Brain wt $(g)$ & $46.90 \pm 9.91$ & $47.68 \pm 4.47$ & 98 \\
\hline Heart wt $(g)$ & $25.93 \pm 4.71$ & $26.90 \pm 3.85$ & 96 \\
\hline Liver wt $(g)$ & $118.45 \pm 55.85$ & $91.68 \pm 25.23$ & 129 \\
\hline Kidney wt (both) $(g)$ & $26.31 \pm 9.52$ & $24.36 \pm 4.84$ & 108 \\
\hline Adrenals wt (both) $(m g)$ & $366 \pm 97$ & $371 \pm 84$ & 99 \\
\hline Thyroid wt $(g)$ & $1.18 \pm 0.58$ & $1.29 \pm 0.31$ & 92 \\
\hline Spleen wt $(g)$ & $6.05 \pm 3.75$ & $6.90 \pm 2.17$ & 88 \\
\hline
\end{tabular}

Right lung fluid was drained and left mainstem bronchus ligated for a mean \pm SD period of $25 \pm 4 \mathrm{~d}$. The values are expressed in mean $\pm \mathrm{SD}$. ${ }^{*} P<0.0025$. The control values were derived from three sham-operated animals and seven unoperated twins. ${ }^{*}$ See text for evaluation of right and left lung fluid volumes in controls.

choline (DSPC) measured in lung tissue, and expressed per unit of DNA content, were not different when comparing the hypoplastic, the hyperplastic, and the control lungs. The measurements of lung lipid content are in the range of published

Table III. Lung Growth and Maturation Following Chronic Lung Liquid Drainage (Right) or Retention (Left) in the Fetal Lamb (Days 105-129 of Gestation)

\begin{tabular}{lccr}
\hline \multicolumn{1}{c}{ Measurement } & $\begin{array}{c}\text { Experimental } \\
(n=5)\end{array}$ & $\begin{array}{c}\text { Control } \\
(n=10)\end{array}$ & $P$ \\
\hline & Mean $\pm S D$ & Mean $\pm S D$ & \\
Right lung (drainage) & & & \\
Wet weight $(g)$ & $24.71 \pm 7.96$ & $59.9 \pm 8.39$ & $<0.001$ \\
Dry weight $(g)$ & $3.226 \pm 1.118$ & $6.591 \pm 1.171$ & $<0.001$ \\
\% Dry weight & $13.12 \pm 1.41$ & $11.03 \pm 0.85$ & 0.003 \\
DNA content $(m g)$ & $175.15 \pm 55.18$ & $346.77 \pm 61.97$ & $<0.001$ \\
mg DNA/g dry wt & $54.78 \pm 2.13$ & $52.19 \pm 2.18$ & 0.048 \\
Protein/DNA & $6.236 \pm 0.572$ & $6.897 \pm 0.427$ & 0.025 \\
Phospholipids (total)* & $100.84 \pm 13.29$ & $104.88 \pm 15.67$ & 0.631 \\
Phosphatidylcholine* & $39.23 \pm 8.97$ & $42.95 \pm 5.85$ & 0.347 \\
DSPC/DNA & $0.325 \pm 0.131$ & $0.345 \pm 0.057$ & 0.676 \\
Hydroxyproline/DNA & $0.260 \pm 0.077$ & $0.211 \pm 0.057$ & 0.189 \\
Left lung (ligation) & & & \\
Wet weight $(g)$ & $125.28 \pm 39.61$ & $39.23 \pm 4.80$ & $<0.001$ \\
Dry weight $(g)$ & $8.073 \pm 2.696$ & $4.466 \pm 0.690$ & 0.001 \\
\% Dry weight & $8.30 \pm 3.10$ & $11.09 \pm 0.79$ & 0.010 \\
DNA content $(m g)$ & $390.74 \pm 103.53$ & $238.85 \pm 33.32$ & 0.001 \\
mg DNA/g dry wt & $49.58 \pm 4.67$ & $53.61 \pm 2.51$ & 0.045 \\
Protein/DNA & $7.330 \pm 0.967$ & $6.680 \pm 0.451$ & 0.093 \\
Phospholipids (total)* & $107.60 \pm 9.07$ & $107.45 \pm 8.54$ & 0.975 \\
Phosphatidylcholine* & $42.18 \pm 4.88$ & $45.39 \pm 7.16$ & 0.386 \\
DSPC/DNA & $0.323 \pm 0.076$ & $0.370 \pm 0.062$ & 0.213 \\
Hydroxyproline/DNA & $0.200 \pm 0.020$ & $0.206 \pm 0.023$ & 0.663
\end{tabular}

DSPC/DNA per mg of disaturated phosphatidylcholine per mg of DNA.

Hydroxyproline is expressed in $\mathrm{mg}$ per $\mathrm{mg}$ of lung DNA.

* Values expressed in $\mathrm{mg} / \mathrm{g}$ of dry weight. values at a comparable gestational age (26). Since the DSPC contents are expressed per unit of total lung DNA, and not specifically per unit of epithelial cell DNA, it is possible that the denominator (DNA) comprises a different mix of cells in the drained lungs as compared with the controls (i.e., with more interstitial and less epithelial cells), thus in effect "diluting" the DSPC values obtained. However, the results of the hydroxyproline content measurements (Table III), taken as an indicator of the proportion connective tissue, do not support this interpretation since no significant differences between experimental and control lungs were found.

In the study of Alcorn et al. (11), alterations in lung maturation were documented by the prevalence and the ultrastructure of type II alveolar epithelial cells. They found more type II cells, containing more lamellar inclusions in the drained lungs than in the control lungs, and the reverse was found in the overexpanded lungs. The design of our study did not allow us to obtain fixed-inflated tissue for analysis. Sections of the lungs were fixed in formaldehyde for light microscopy and we were not able to distinguish with certainty type I and type II cells.

It should be noted that this discrepancy of findings between biochemical and morphological studies is the rule rather than the exception. When considering animal models of lung hypoplasia in various species (sheep, rabbit, and guinea pig) for instance, the concentration of surfactant per unit of lung DNA was invariably found to be unaffected (27-30). In contrast, ultrastructural studies of hypoplastic lungs in animal models have suggested advanced maturation as indicated by excess type II alveolar epithelial cells in most instances $(11,31,32)$, but not invariably (33). In no instances were detailed measurements of both lipid contents and ultrastructure presented simultaneously. There is no clear explanation for this discrepancy in results between biochemical and morphological studies; this crucial issue will need to be addressed in future studies.

The choice to end the experimental period around day 130 of gestation was made to allow comparisons with the work of Alcorn et al. (11). However, it could be argued that it was a suboptimal choice given that so many maturational changes occur in the fetal lamb lung around that time in gestation. 
The average volume and flow of lung liquid drained from the right lung over the $25 \mathrm{~d}$ of the experimental period represent $\sim 50 \%$ of the values obtained by Alcorn et al. (11) who drained the whole lung during a similar period. This would suggest that lung fluid balance is rather tightly controlled at the tissue level rather than by the organ as a whole.

To our surprise, there was no major mediastinal shift to the right observed at the time of necropsy in the experimental animals (see Fig. 3). Rather, there was a deformation of the ribcage, which was slightly "barrelshaped", with an inversion of the diaphragm on the left side, while it was narrow with an elevated diaphragm on the right side (see Fig. 2). This apparent mediastinal "stiffness" in the fetal lamb was further evidenced in two animals when luminal pressures were recorded simultaneously from the right and the left lung. Fetal breathing movements led to the typical negative pressure swings on the right side and to positive pressure swings on the left side (where the diaphragm was inverted). The lack of a major mediastinal shift to the right was an important finding, as the lung hypoplasia observed on the right side could have been the result of compression alone, i.e., mediastinum pushed to the right by the distended left lung. Conversely, the lung hyperplasia seen on the left side could have been the result of increased intrathoracic space made available by the drained right lung, i.e., mediastinum pulled to the right.

The asymmetry in configuration of the ribcage, narrow on the hypoplastic side and broad on the hyperplastic side, is of interest and may indicate that fetal lung volume plays a role in determining the growth and ultimate shape of the thoracic cavity. Thus, the narrow "pigeon chest" occasionally observed in newborn infants with lung hypoplasia, whether associated with oligohydramnios or with neuromuscular diseases, may in fact not indicate thoracic compression leading to small lungs but rather delayed lung growth (from another cause) leading to narrow thoraces.

The two animals in which the left mainstem bronchus ligation was incomplete with persistence of a pinhole track, are of relevance when comparing their normal left lung DNA findings with the lung DNA measurements in human fetuses with congenital laryngeal atresia (14). For in that report, the persistence of a pinhole epithelial-lined pharyngotracheal duct through which droplets of lung liquid could be expressed on pressure was also described, possibly explaining why lung DNA contents were not found to be increased (14).

In summary, this study demonstrates the crucial role played by local lung fluid dynamics on fetal lung growth. Chronic drainage of fetal lung liquid leads to significant lung hypoplasia, whereas chronic retention of fetal lung liquid leads to significant lung hyperplasia in the presence of a common endocrine milieu. Neither hypoplastic nor hyperplastic lungs showed biochemical evidence of altered maturation. These findings demonstrate that fetal lung cell multiplication is influenced by local distending forces, while the biochemical maturation of fetal lung surfactant is under systemic control.

\section{Acknowledgments}

The authors thank Dr. I. C. McMillen, Ms. Valerie Ford, and Dr. G. F. Peart for the performances of the cortisol, epinephrine, and hydroxyproline assays, respectively. We also thank Drs. K. A. Dickson, S. B. Hooper, R. I. Young, and Ms. Julie Norman and Kerryn Billings for surgical and technical assistance.

\section{References}

1. Editorial: Leads from the MMWR. 1988. Premature mortality due to congenital anomalies-United States. J. Am. Med. Assoc. 260:185.

2. Moessinger, A. C., A. Santiago, N. S. Paneth, H. R. Rey, W. A. Blanc, and J. M. Driscoll, Jr. 1989. Time-trends in necropsy prevalence and birth prevalence of lung hypoplasia. Paediatr. Perinatal Epidemiol. 3:421-431.

3. Liggins, G. C., and J. A. Kitterman. 1981. Development of the fetal lung. In The Fetus and Independent Life. K. Elliot and Whelan, editors. Ciba Symposium 86. Pittman Books Ltd., London. 308-322.

4. Kitterman, J. A. 1984. Fetal lung development. J. Dev. Physiol. (Oxf.). 6:67-82.

5. Liggins, G. C., and J.-C. Schellenberg. 1985. Aspects of fetal lung development. In The Physiological Development of the Fetus and Newborn. C. T. Jones and P. W. Nathanielsz, editors. Academic Press Limited (AP), London. 179-189.

6. Harding, R. 1986. The upper respiratory tract in perinatal life. In Respiratory Control and Lung Development in the Fetus and Newborn. B. M. Johnston and P. D. Gluckman Editors. Perinatology Press, Ithaca, NY. 331-376.

7. Liggins, G. C., G. A. Vilos, G. A. Campos, G. A. Kitterman, and C. H. Lee. 1981. The effect of bilateral thoracoplasty on lung development in the fetal sheep. J. Dev. Physiol. 3:275-282.

8. Fewell, J. E., A. Hislop, J. A. Kitterman, and P. Johnson. 1983. Effect of tracheostomy on lung development in fetal lambs. J. Appl. Physiol. 55:1103-1108.

9. Jost, A., and A. Policard. 1948. Contribution experimentale a l'etude du development prenatal du poumon chez le lapin. Arch. Anat. Microsc. Morphol. Exp. 37:323-332.

10. Carmel, J. A., F. Friedman, and F. H. Adams. 1965. Fetal tracheal ligation and lung development. Am. J. Dis. Child. 109:452456.

11. Alcorn, D., T. M. Adamson, T. F. Lambert, J. E. Maloney, B. C. Ritchie, and P. M. Robinson. 1977. Morphological effects of chronic tracheal ligation and drainage in the fetal lamb lung. J. Anat. 123:649-660.

12. Wigglesworth, J. S., and R. Desai. 1979. Effects on lung growth of cervical cord section in the rabbit fetus. Early Hum. Dev. 3:51-65.

13. Potter, E. L. 1946. Bilateral renal agenesis. J. Pediatr. 29:68-76.

14. Wigglesworth, J. S., R. Desai, and A. A. Hislop. 1987. Fetal lung growth in congenital laryngeal atresia. Ped. Pathol. 7:515-525.

15. Scurry, J. P., T. M. Adamson, and L. J. Cussen. 1989. Fetal lung growth in laryngeal atresia and tracheal agenesis. Aust. Paediatr. J. 25:47-51.

16. Silver, M. M., W. A. Thurston, and J. E. Patrick. 1988. Perinatal pulmonary hyperplasia due to laryngeal atresia. Hum. Pathol. 19:110-113.

17. Moessinger, A. C., R. Harding, T. M. Adamson, M. Singh, and G. T. Kiu. 1989. Local versus systemic factors at play in fetal lung growth and maturation. Pediatr. Res. 25:56. (Abstr.)

18. Munro, H. N., and A. Fleck. 1966. Recent developments in the measurement of nucleic acids in biological material. Analyst. 91:7888.

19. Lowry, O. H., N. J. Rosebrough, A. L. Farr, and R. J. Randall. 1951. Protein measurement with the Folin phenol reagent. J. Biol. Chem. 193:265-275.

20. Folch, J., M. Leles, and G. H. S. Stanley. 1957. A simple method for the isolation and purification of total lipids from animal tissues. J. Biochem. 226:497-509.

21. Bartlett, G. R. 1959. Phosphorus assay in column chromatography. J. Biol. Chem. 234:466-468.

22. Mason, R. J., J. Nellenbogen, and J. A. Clements. 1976. Isolation of disaturated phosphatidylcholine with osmium tetroxide. $J$. Lipid Res. 17:281-284.

23. Kivirikko, K. E., O. Laitinen, and D. J. Prockop. 1967. Modifi- 
cations of a specific assay for hydroxyproline. Anal. Biochem. 19:249-255.

24. Bocking, A. D., I. C. McMillen, R. Harding, and G. D. Thorburn. 1986. Effect of reduced uterine blood flow on fetal and maternal cortisol. J. Dev. Physiol. 8:237-245.

25. Schuijers, J. A., D. W. Walker, C. A. Browne, and G. D. Thorburn. 1986. Effect of hypoxemia on plasma catecholamines in intact and immunosympathectomized fetal lambs. Am. J. Physiol. 251:R893-R900.

26. Brumley, G. W., V. Chernick, W. A. Hodson, C. Normand, Fenner, and M. E. Avery. 1967. Correlations of mechanical stability, morphology, pulmonary, surfactant, and phospholipid content in the developing lamb lung. J. Clin. Invest. 46:863-873.

27. Liggins, G. C., G. A. Vilos, G. A. Campos, J. A. Kitterman, and C. H. Lee. 1981. The effect of spinal cord transection on lung development in fetal sheep. J. Dev. Physiol. 3:267-274.

28. Fewell, J. E., C. H. Lee, and J. A. Kitterman. 1981. Effects of phrenic nerve section on the respiratory system of fetal lambs. J. Appl. Physiol. 51, 2:293-297.

29. Wigglesworth, J. S., and R. Desai. 1979. Lung phospholipids in rabbit fetal lung hypoplasia. Pediatr. Res. 13:365. (Abstr.)

30. Moessinger, A. C., M. Singh, D. F. Donnelly, G. Haddad, G., M. H. Collins, and L. S. James. 1987. The effect of prolonged oligohydramnios on fetal lung development, maturation and ventilatory patterns in the newborn guinea pig. J. Dev. Physiol. 9:419-427.

31. Alcorn, D., T. M. Adamson, J. E. Maloney, and P. M. Robinson. 1980. Morphological effect of chronic bilateral phrenectomy or vagotomy in the fetal lamb lung. J. Anat. 130:683-695.

32. Pringle, K. C., J. W. Turner, J. C. Schofield, and R. T. Soper. 1984. Creation and repair of diaphragmatic hernia in the fetal lamb: lung development and morphology. J. Pediatr. Surg. 19:131-140.

33. Nagai, A., W. M. Thurlbeck, A. H. Jansen, S. Ioffe, and V. Chernick. 1988. The effect of chronic biphrenectomy on lung growth and maturation in fetal lambs. Am. Rev. Respir. Dis. 137:167-172. 